\section{Matéria}

ISSN 1517-7076
Revista Matéria, v. 11, n. 2, pp. 88 - 100, 2006

http://www.materia.coppe.ufrj.br/sarra/artigos/artigo10677

\title{
Combined Micro-Hardness and Eddy Currents Applied to the Study of Steel Decarburizing
}

\author{
D. Mercier, D. Chicot. \\ Laboratoire de Mécanique de Lille, LML UMR 8107, U.S.T. Lille, \\ IUT A GMP, BP 179 - 59653 Villeneuve d'Ascq Cedex, France. \\ e-mail: david.mercier@univ-lille1.fr, didier.chicot@univ-lille1.fr.
}

\begin{abstract}
Carbon is the most important element going in the steels composition since it largely contributes to their mechanical performance. During the heat treatment of steels, a part of atoms of carbon could be removed from the superficial zone of the steel, which is the result of the atmospheric oxygen attraction by forming gaseous carbon monoxide. This phenomenon, called decarburizing, can change microstructure in a large extent and, as a result, mechanical properties of the steel. This could lead to unsuitable properties for the service life of mechanical parts. In order to prevent such part from breaking in service, it is necessary to know the affected zone by the decarburizing process.

For this purpose, the most used technique is a visual observation by optical microscopy of a cross section of the material. This technique is often associated to the hardness profile obtained by Vickers or Knoop indentations in the same section. Depending on the material and on the specimen preparation, some discrepancies are often observed between the two informations. On the other hand, these techniques require a long preparation and cautious interpretation. Then we propose here to use eddy current testing, which is widely employed to detect fatigue cracks, to give some information about changes in microstructure and to examine carburizing of steel from both mechanical and microstructural point of view. For carburizing, eddy current has been successfully connected to the increase of micro-hardness near the surface. This last result has particularly motivated us to use eddy current to analyze decarburizing.

In the present work, different durations in the furnace at a temperature of $920^{\circ} \mathrm{C}$ before oil quenching were performed on 54SiCrV6 (SAE 92V45) steel in order to obtain various morphologies of the decarburized zone. We show that eddy current test may be used to qualify the level of decarburizing since, after a convenient Fourier transformation, three components of the amplitude of the signal are directly linked to the duration of the heat treatment. Associated to optical and hardness measurements, it is also shown that the eddy current signal is well related to the decarburizing depth.
\end{abstract}

Keywords: Decarburizing, eddy current, carbon diffusion, microstructure, micro-hardness.

\section{$1 \quad$ INTRODUCTION}

During manufacturing of mechanical parts, a phenomenon of decarburization can occur during the heat treatment of the material. This phenomenon results in the diffusion of carbon at high temperature throughout the surface of the material due to reaction with oxygen atmosphere, which produced carbon monoxide. This loss of carbon leads to superficial microstructure modifications, which involves deterioration of the mechanical properties. Unfortunately, the literature shows that decarburization of steel is a phenomenon slightly studied during these last decades. However, some works devoted to the study of decarburization effects on microstructure of steel [1 $\underline{-3}]$, on the resistance of corrosion [4] and on the fatigue behaviour [5, 6] could be found. By analysing this literature, it appears necessary to have suitable means of decarburization control, as much more than such phenomenon have detrimental effect from a mechanical behaviour point of view. This is the reason why decarburization control is, until today, generally carried out in two complementary directions.

The first one consists of an optical observation of the microstructure on a cross section of the sample, which has undergone a treatment at elevated temperature. When no decarburizing occurs, the microstructure is that expected by the treatment. Depending on the cooling rate, microstructure can exhibit a ferrite / pearlite structure for slow cooling rate or martensite, bainite and retained austenite for the fastest ones in the majority of the cases. Due to decarburizing process in the austenitic phase, number of atoms of 
carbon decrease close to the surface. As a consequence, distribution of phases and/or change of atoms content in the phases tend to be modified after cooling. For the martensite, loss of atoms of carbon involves diminution of the lattice parameters ratio, which is linked to the carbon content $[7,8]$. This modification tends to transform martensite tetragonal into body centred ferrite. Whatever the cooling rate, a white zone corresponding to a great amount of ferrite or a carbon martensite slightly charged is spread out over a few microns of depth. The problem of the optical control is the determination of the limit between the decarburized zone and the core one, which is the most convenient information for the decarburizing characterisation. This is so difficult than measurement depends on the operator. That is why another method is also used to reinforce the first control. The second method consists to study micro-hardness variation induced by modification of distribution of phases and on the carbon content of some phases. Micro-hardness profile is then realized through a cross section. The limit between the two above-mentioned zones is then defined when hardness becomes constant and equal to the hardness value of the healthy material. These two methods are obviously destructive. In order to avoid such detrimental method, we test here an alternative method based on eddy current, which appears to be a non-destructive testing.

Restivo in 1996 [9] has specified the theory relating to the eddy current whereas Yusa [10] applies the theory to detect surface defect. From this point of view, this technique has been applied to control crack initiation and growth during fatigue test [11]. Being used to analyse defects, Uchimoto [12] has tested eddy current to study modifications of microstructure and, in particular, graphite morphology associated to the mechanical properties of grey and ductile cast iron made. For case-carburised steel, Stevens [13] confirm that this method can also be used to determine the microstructure state. In addition, Moorthly [14] and Zergoug [15] proposed to connect the mechanical micro-hardness modifications induced by carburizing to eddy current variations. This last result encourages us to apply eddy current methodology to the study of decarburized steel.

In order to study different situations of decarburizing, samples are heat treated at $920^{\circ} \mathrm{C}$ during different durations. In the first part of the paper, we show that optical control and micro-hardness profile of the decarburization zone may be supported by the theory of carbon diffusion in steel. In a second part, eddy current analysis is successfully applied to qualify the decarburization if all harmonics amplitudes deduced from Fast Fourier Transformation (FFT) are used. By comparing optical and micro-hardness measurements of depths, we show that the eddy current may be suitable to the control of decarburized parts.

\section{EDDY CURRENT THEORY.}

Fluctuating electromagnetic fields are created within a test object by passing an alternative current through a nearby primary (driving) coil. These fluctuating electromagnetic fields induce eddy currents in the sample. The eddy currents create a secondary electromagnetic field, which perturbs that of the primary coil. This can be detected either as a change in the impedance of the primary coil (the basis of single coil methods) or by monitoring the response induced in a nearby secondary coil (the two coil method). At low and medium excitation frequencies the eddy current magnitude is a function of the sample's electrical conductivity, magnetic permeability, the test frequency and the distance between the coils and the sample. When a sample is located in the magnetic field, modifications of the eddy current lines are observed. These modifications lead to a variation of the real part of the impedance. Thus, for a sinusoidal alternative current passing through a bobbin coil of $\mathrm{N}$ turn spirally wound, the impedance is defined by the Ohm's law :

$$
\stackrel{\mu}{Z}=\stackrel{\mu}{V} / \stackrel{\mu}{i}
$$

where $\hat{V}$ and $\underset{i}{\sim}$ are the complex vectors of Fresnel respectively associated to the tension and the intensity. In addition, $\hat{V}$ and $\underset{i}{i}$ are linked to the complex reluctance $(\mathrm{R})$ of the magnetic circuit and to the magnetic flux $(\Phi)$ by the following relationships:

$$
\mathrm{Ni}=\stackrel{\mu}{\mathrm{R}} \dot{\phi}
$$

and

$$
\stackrel{\mu}{V}=\mathrm{jN} \omega \stackrel{\mu}{\phi}
$$

where $\omega$ is the current pulsation.

From relation (1), these two relations allow determining the complex impedance, which may be written: 
The inductive tensor is characterized by two physical quantities:

- The resistive component (R), associated to the loss of eddy current,

- The inductive term $(\mathrm{X})$, which represents the reactance of the bobbin and thus, the topology of the magnetic field lines.

The impedance change of the probe can be represented by the variation of the impedance response in function of the time. Fast Fourier Transform (FFT) decomposes a time-domain signal, which can be a function of time, spatial coordinates or any time series abscissa, into frequency spectrum expressed with complex exponentials (sinus and cosinus). Here, it is applied to a signal of frequency $\mathrm{F}_{0}$ studied with 256 points per period. For these conditions, the FFT allows to decompose the signal and to obtain the values of amplitudes and phases of harmonics 3,5 and 7. The main interest of studying the harmonics instead of the main signal is that they do not represent a surface characterisation. Moreover, they are less sensitive to temperature variations and signal deviations due to the position of the sample within the inductor and/or to its geometry.

\section{MATERIALS AND EXPERIMENTAL METHODS.}

The present investigation was conducted with specimens of 54SiCrV6 (SAE 92V45) steel for which chemical composition is given in Table 1 .

Table 1: Chemical composition in weight percent

\begin{tabular}{l|l|l|l|l|l|l|l|l|l|l|l}
\hline Steel & $\mathrm{C}$ & $\mathrm{Mn}$ & $\mathrm{S}$ & $\mathrm{P}$ & $\mathrm{Ni}$ & $\mathrm{Cr}$ & $\mathrm{Mo}$ & $\mathrm{Cu}$ & $\mathrm{Sn}$ & $\mathrm{Ti}$ & $\mathrm{V}$ \\
\hline 54SiCrV6 & 0,555 & 0,680 & 0,015 & 0,008 & 0,075 & 0,510 & 0,025 & 0,185 & 0,013 & 0,001 & 0,125 \\
\hline
\end{tabular}

Specimens of $20 \mathrm{~mm}$ in diameter and $100 \mathrm{~mm}$ in length were cut from bars which metallurgical state is ferrito-pearlitic. In order to obtain different situations of decarburizing, all the samples were maintained at a temperature of $920^{\circ} \mathrm{C}$ during eight different times ranging regularly from 15 to 120 minutes. This temperature was chosen in order to obtain complete dissolution of the carbides in austenite. The samples are then oil-quenched in order to induce martensitic transformation. Samples were referenced from A to H according to the austenitisation time.

The micro-hardness profile is obtained with a Knoop indenter using a Leco micro-hardness tester. For each situation of austenitizing durations, five indentations are performed under $1 \mathrm{~N}$ of loading on a cross section perpendicular to the decarburizing surface in order to give a representative mean hardness value. The first hardness measurement is carrying out at $20 \mu \mathrm{m}$ of the outside surface and all the $20 \mu \mathrm{m}$ until $700 \mu \mathrm{m}$ toward the core of the material.

The eddy current equipment used was the Alphatest OMEGA 2000. The synoptic of a typical measurement is presented Figure 1. The generator provides a sinusoidal current, which frequency $\mathrm{F}$ can be set from $0,5 \mathrm{~Hz}$ to $3 \mathrm{KHz}$ and intensity I from 0,1 to $10 \mathrm{Amp}$. 


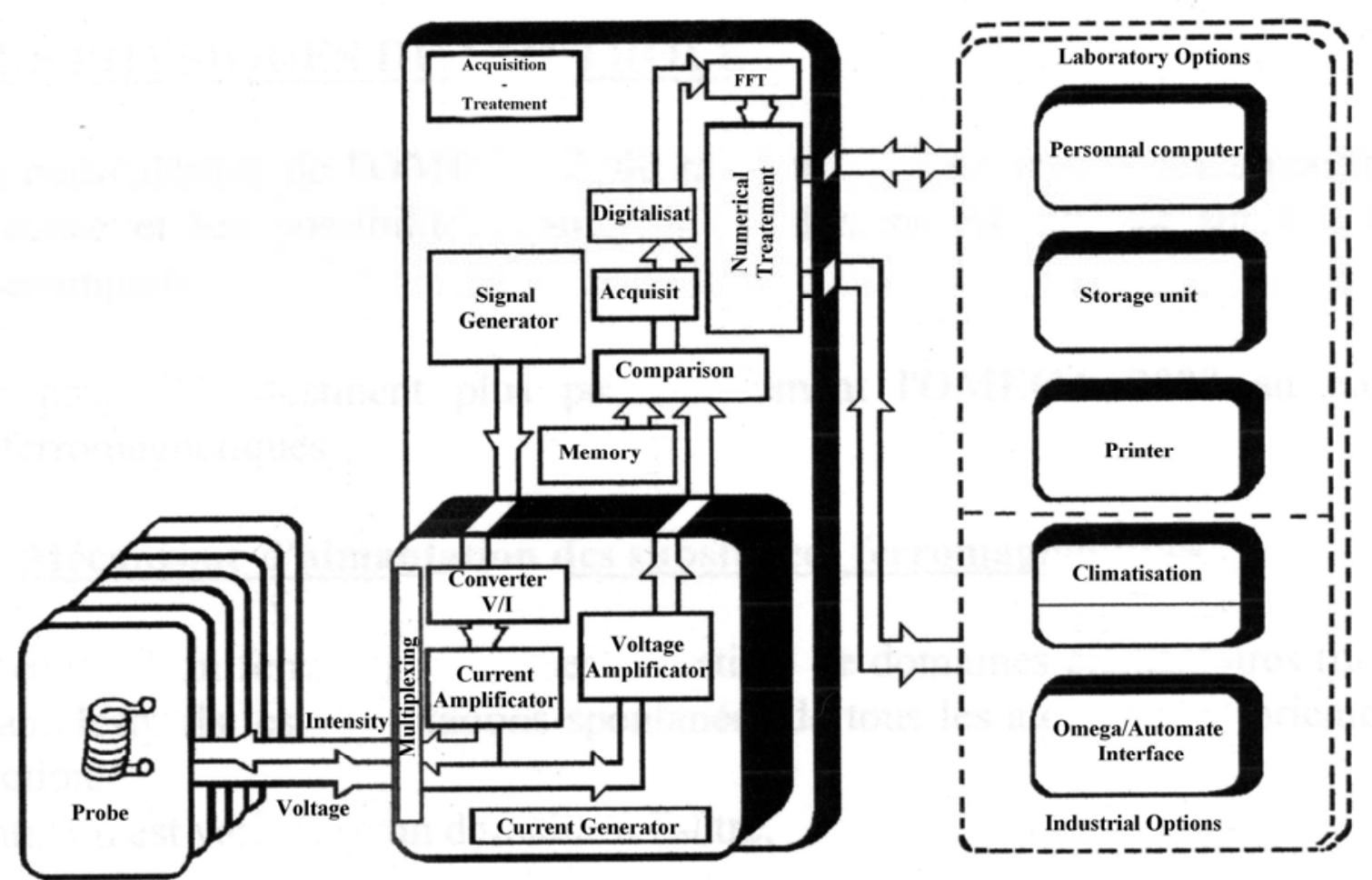

Figure 1: General synoptic of the experimental apparatus (OMEGA 2000).

The output tension was recorded for various couples $I_{i}$ and $F_{i}$ and submitted to Fast Fourier Transformation. This transformation providing the phase and the frequency spectrum, it's possible to describe the fundamental and as well as its harmonics. Here the study was limited to the harmonics 3, 5 and 7 associated to each sample. The data are then computed by using a second-degree polynomial fitting for each parameter (amplitude and phase) in relation to the austenitizing time.

\section{RESULTS AND DISCUSSION.}

\subsection{Optical observations.}

After austenitizing and oil quenching, the samples were sectioned and polished with paper grade from 6 to $1 \mu \mathrm{m}$ diamond and then etched in Nital 4\%. Figure 2 shows an example of a decarburized sample typical appearance.

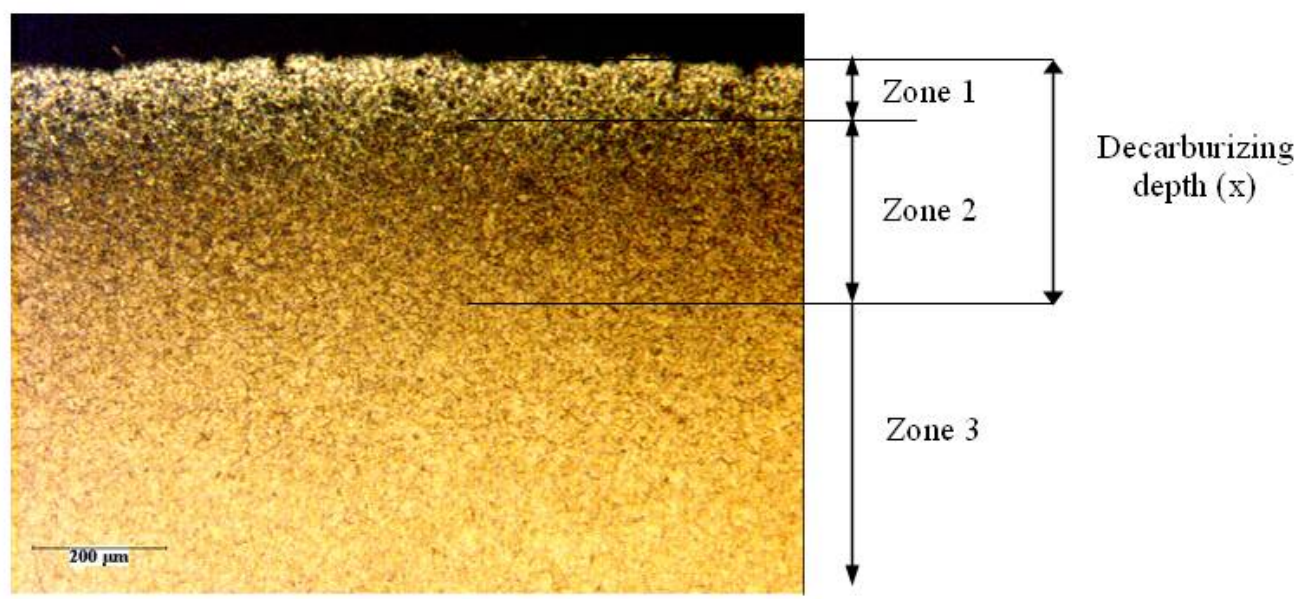

Figure 2: Optical micrograph of the cross section of a sample austenitised during 105 minutes. 
Three zones of different colour can be noticed on Figure 2. Close to the surface, the colour is mainly white and corresponds to a structure entirely made up of ferrite or very low carbon martensite. Towards the core, the colour is darker but show some white spots. These correspond to lower carbon martensite associated to spots of ferrite, located where the diffusion of carbon was easier (grain boundaries for example). In the core, the colour is homogeneous and associated to a martensite including initial carbon content of steel. The decarburizing depth is associated to the change of colour between zone two and three. Since the change is very gradual, it is difficult to localize precisely the boundary between the affected surface and the core of the material. Table 2 gives an estimation of the total decarburizing depths for all samples. The decarburizing depths were carried out with the standard defined in [16].

Table 2: Total decarburizing depth estimated by optical measurement .

\begin{tabular}{l|l|l|l|l|l|l|l|l}
\hline Sample & A & B & C & D & E & F & G & H \\
\hline Austenitizing time $(\mathrm{t}$ in $\mathrm{mn})$ & 15 & 30 & 45 & 60 & 75 & 90 & 105 & 120 \\
\hline Decarburizing depth $(\mathrm{x} \pm 15$ in $\mu \mathrm{m})$ & 0 & 90 & 95 & 155 & 185 & 245 & 280 & 320 \\
\hline
\end{tabular}

As it was expected, the decarburizing depth increases with the austenitizing time. Since it is governed by the carbon diffusion in austenite, the decarburizing process should satisfy the diffusion equations of Fick. We will examine how the relation depth-time can be explained by the carbon diffusion theory. Applied to the problem of carbon diffusion from the surface to the material core, the solution of second Fick's law takes the following form:

$$
C(x, t)=C_{0}+\left(C_{S}-C_{0}\right)\left\{1-\frac{2}{\sqrt{\pi}} \int_{0}^{x / 2 \sqrt{D t}} \exp \left(-y^{2}\right) d y\right\}
$$

where $C(x, t)$ represents the carbon content at a depth $x$ from the surface of the sample, $C_{S}$ is the carbon concentration at the surface, $\mathrm{C}_{0}$ the initial carbon concentration of the steel. $\mathrm{D}$ is the diffusion coefficient of carbon in austenite, which is given by:

$$
\mathrm{D}=\mathrm{D}_{0} \exp \left(-\mathrm{Q}_{\mathrm{A}} / \mathrm{RT}\right)
$$

Here, $\mathrm{D}_{0}$ represents the diffusivity coefficient. $\mathrm{Q}_{\mathrm{A}}$ is the activation energy for the diffusion of carbon in austenite. $\mathrm{R}$ is the perfect gas constant equal to $8.314 \mathrm{~J} \cdot \mathrm{mol}^{-1} \cdot \mathrm{K}^{-1}$.

Different values for the diffusivity coefficient can be found in literature: for example 0.1 for Roy [17] or $0.234 \mathrm{~cm}^{2} \mathrm{~s}^{-1}$ for Gamsjager [18]. In their studies, Lan [19] and Kumar [20] used an intermediate value of $0.17 \mathrm{~cm}^{2} \mathrm{~s}^{-1}$. For the activation energy, Golovin [21] gives two limits depending on the chromium content in the steel : $135 \mathrm{~kJ} \mathrm{~mol}^{-1}$ for steel without chromium and $145 \mathrm{~kJ} \mathrm{~mol}^{-1}$ for steel with it. Gamjager [18] and Agren [16] have used $148 \mathrm{~kJ} \mathrm{~mol}^{-1}$ and Lan [19] and Kumar [20], $143.3 \mathrm{~kJ} \cdot \mathrm{mol}^{-1}$.

All these values are sufficiently closed to choose $\mathrm{D}_{0}=0.17 \mathrm{~cm}^{2} \mathrm{~s}^{-1}$ and $\mathrm{Q}_{\mathrm{A}}=145 \mathrm{~kJ}_{\mathrm{mol}} \mathrm{m}^{-1}$ taking into account the presence of chromium in the material (see Table 1). By considering these values, it is possible to calculate a diffusion coefficient equal to $\mathrm{D}=7.610^{-8} \mathrm{~cm}^{2} \mathrm{~s}^{-1}$ at $920^{\circ} \mathrm{C}$.

Futhermore, the depth of decarburizing (Table 2), as it is optically measured, should correspond to a concentration $\mathrm{C}(\mathrm{x}, \mathrm{t})=\mathrm{C}_{\mathrm{opt}}$ closed to the initial value of the carbon content of the material independently of the austenitizing duration. In these conditions, the second term of relation (5) should be a constant and is written as an erf(y) function:

$$
\left\{1-\frac{2}{\sqrt{\pi}} \int_{0}^{\mathrm{x} / 2 \sqrt{\mathrm{Dt}}} \exp ^{-y^{2}} \mathrm{dy}\right\}=\left\{1-\operatorname{erf}\left(\frac{\mathrm{x}}{2 \sqrt{\mathrm{Dt}}}\right)\right\}=0
$$

This means that it exists a value $k$, which satisfies the following relation: 


$$
\frac{\mathrm{x}}{2 \sqrt{\mathrm{Dt}}}=\mathrm{k} \quad \text { or } \quad \mathrm{x}=2 \cdot \mathrm{k} \cdot \sqrt{\mathrm{Dt}}
$$

Representing the decarburizing depth as a function of the square root of the austenitizing time, we find a straight line according to relation (8) as it is shown Figure 3.

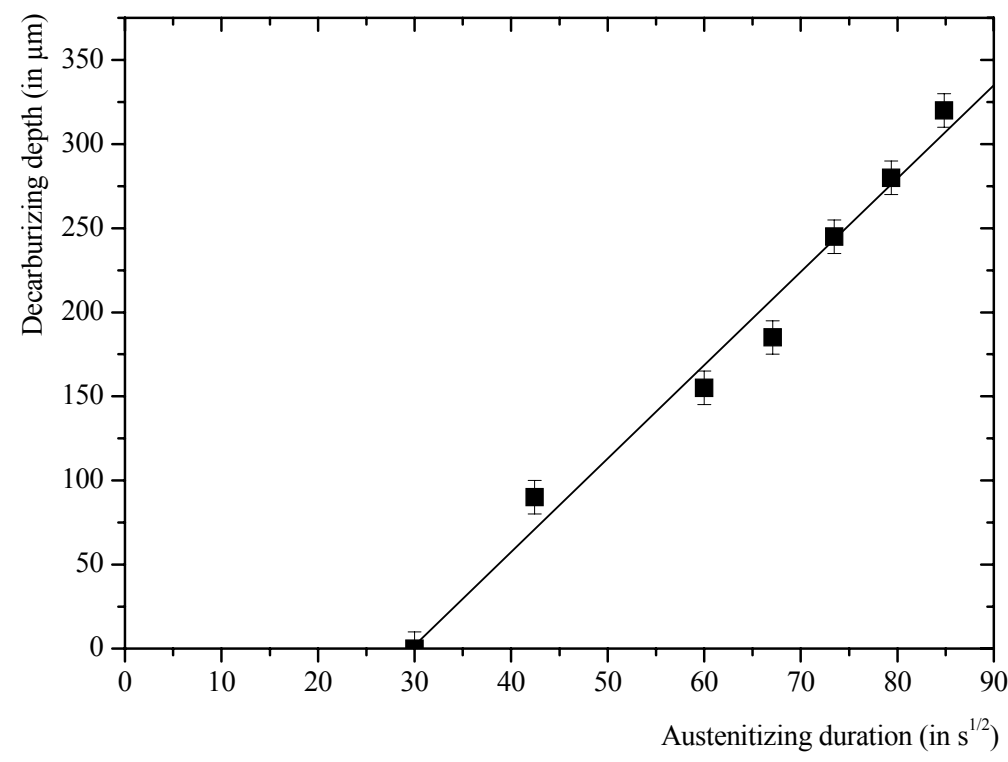

Figure 3: Decarburizing depth according to the square root of the austenitizing time.

It is noticed on the figure that the straight line does not intercept the axes at the origin point $(0,0)$. This seems to indicate that the samples need a substantial time to reach the diffusion temperature of $920^{\circ} \mathrm{C}$. Figure 4, related to the sample A heat treated during $15 \mathrm{mn}$, shows that no decarburizing is observable and corroborates its assumption.

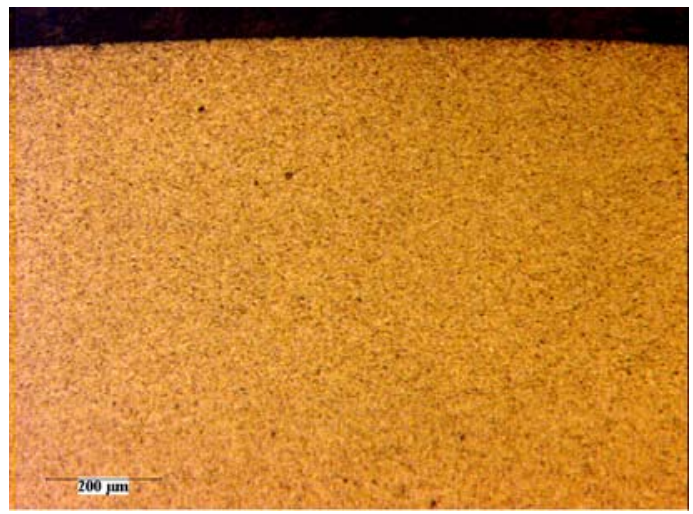

Figure 4: Optical micrograph of steel surface after a 15 minute treatment.

If it is assumed in relation (5) that $\mathrm{C}_{\mathrm{s}}$ is equal to 0 then $\mathrm{C}(\mathrm{x}, \mathrm{t})$ should be equal to :

$$
C(x, t)=C_{0} \cdot \operatorname{erf}\left(\frac{x}{2 \sqrt{D t}}\right)=C_{0} \cdot \operatorname{erf}(k)
$$


In this condition, $\operatorname{erf}(\mathrm{k})$ should be equal to 1 at the boundary of the decarburizing zone. From equation (8), it is possible to calculate $\mathrm{k}$ from the slope $\mathrm{s}$ of the straight line in Fig. 3. Calculation of $\mathrm{s}$ gives $5.65 .10^{-4} \mathrm{~cm} . \mathrm{s}^{-1 / 2}$ and then $\mathrm{k}$ is equal to 1 . Consequently, $\operatorname{erf}(\mathrm{k})=0.84$ (i.e. $84 \%$ of the initial carbon content $\mathrm{C}_{0}$ of the steel according to relation (9)). This means that optical measurements lead to underestimated decarburized depth values.

\subsection{Micro-hardness Measurements.}

Relation between micro-hardness and microstructure of material is well known [22, 23]. In addition to the relation between the hardness and the nature of the phases, micro-hardness strongly depends on the carbon content of the phase, especially for the martensite. Consequently, hardness values of decarburized steel can be varied in a great extent. Figure 5 shows two profiles of micro-hardness obtained for the samples austenitized during 15 minutes $(\mathrm{A})$ and 120 minutes $(\mathrm{H})$, which correspond to the two time limits.

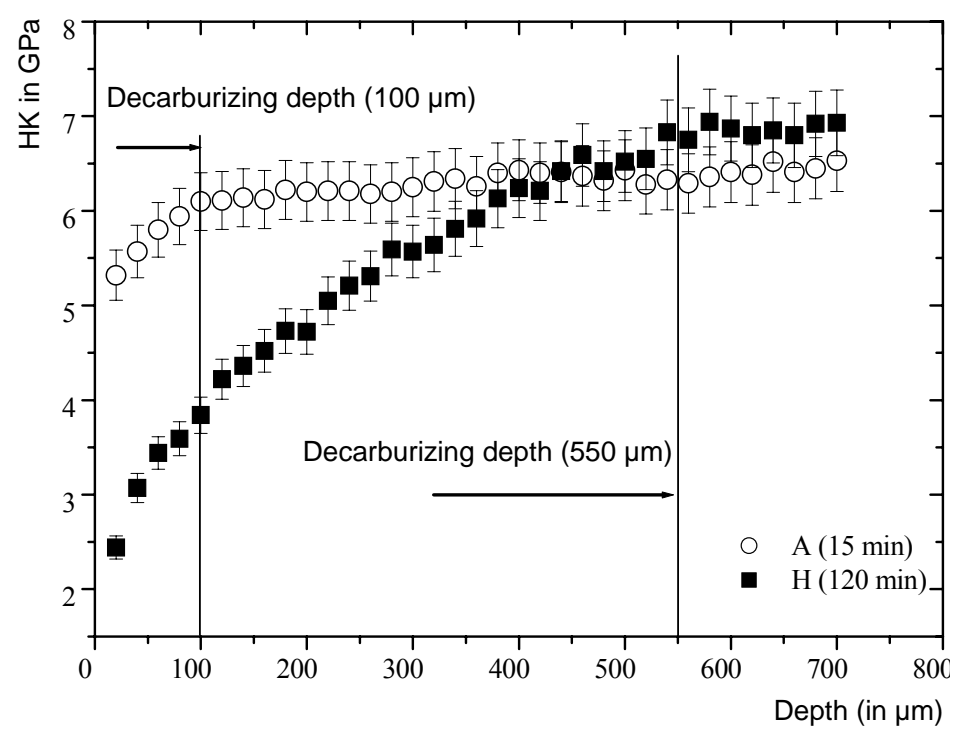

Figure 5: Micro-hardness evolution for decarburized steels during 15 and $120 \mathrm{~min}$.

For all the studied specimens, we have observed that micro-hardness variations are located between the two curves presented on Figure 5. It is seen that the curves can be divided into two zones. The first one at the left corresponds to the decarburized zone where the hardness values vary, this zone being close to the surface. The second zone at the right of the figure corresponds to the core of the material where hardness values are almost the same. As an example, it can be seen on Figure 5 that decarburizing depth is estimated to $100 \mu \mathrm{m}$ for sample A and $550 \mu \mathrm{m}$ for sample H. Table 3 collects the decarburizing depths obtained for each treatment situation.

Table 3: Decarburizing depth estimated from hardness measurements.

\begin{tabular}{l|l|l|l|l|l|l|l|l}
\hline Sample & A & B & C & D & E & F & G & H \\
Austenitizing duration $(\mathrm{t}$ in $\min )$ & 15 & 30 & 45 & 60 & 75 & 90 & 105 & 120 \\
Decarburizing depth $(\mathrm{x} \pm 20$ in $\mu \mathrm{m})$ & 100 & 180 & 260 & 350 & 330 & 410 & 490 & 550 \\
\hline
\end{tabular}

Data of Table 3 are presented on Figure 6 as a function of the square root of the austenitizing time. Data from optical observations are also represented to allow a comparison. 


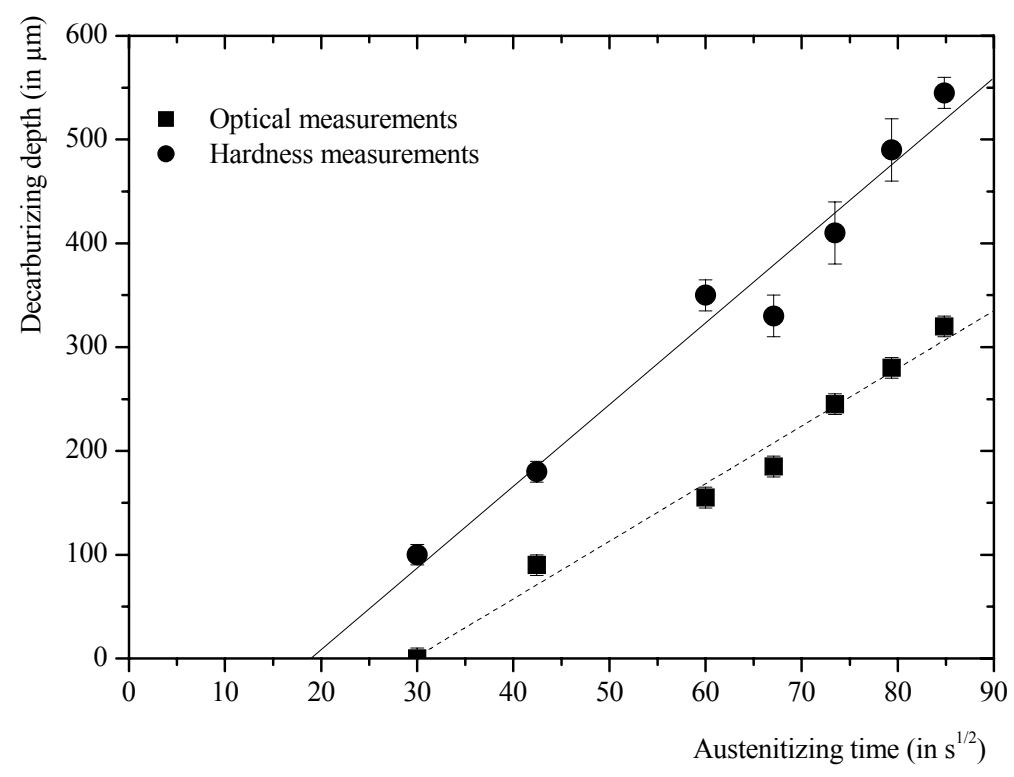

Figure 6: Decarburizing depth depending on the square root of the austenitizing time.

Like the optical observations, the line associated to hardness measurements does not intersect the axes at the origin but at a point corresponding to an austenitizing time near $5 \mathrm{mn}$. This seems to indicate that an incubation time is necessary for decarburizing initiation. This incubation time can be a consequence of a delay necessary for the carbides dissolution. Such incubation is similar to the incubation time necessary for the onset of a nitride combination layer during nitriding [24]. Concerning the slope s of the line, it is found equal to $7.9310^{-4} \mathrm{~cm}^{-1 / 2} \mathrm{~s}^{-}$associated to a constant $\mathrm{k}$ near 1.44 corresponding to $\operatorname{erf}(1.44)=0.96$ (i.e. $96 \%$ of the initial carbon content). In conclusion, micro-hardness measurements are more accurate than optical measurements for the determination of the decarburizing depth. Even if they are able to give precise estimations of decarburised depth, the hardness measurements are destructive which is a disadvantage for mechanical parts control. In the following, we will present a method that could be used for non destructive characterization of decarburizing.

Nevertheless, like these two measurements are destructives, we proposed in the second part to examine how the eddy current technique could be used to characterize the decarburizing. For the eddy current study, only the decarburizing depth deduced from micro-hardness measurements are taken into account due to the results accuracy.

\section{EDDY CURRENT STUDY}

Applying to all samples the methodology described in the experimental methods and measurements section of the paper, we have obtained a complete description of the output tension signal (fundamental and harmonics). The harmonics 3, 5 and 7 which be used in the following to characterize the decarburizing are presented in Table 4.

Table 4: Real and imaginary parts from signal decomposition.

\begin{tabular}{|c|c|c|c|c|c|c|c|c|c|}
\hline \multicolumn{2}{|l|}{ Sample } & $\mathrm{A}$ & $\mathrm{B}$ & $\mathrm{C}$ & $\mathrm{D}$ & $\mathrm{E}$ & $\mathrm{F}$ & $\mathrm{G}$ & $\mathrm{H}$ \\
\hline \multicolumn{2}{|l|}{ Time of austenitizing (minutes) } & 15 & 30 & 45 & 60 & 75 & 90 & 105 & 120 \\
\hline \multirow{3}{*}{$\begin{array}{l}\text { Imaginary part of the harmonic } \\
\text { (in rad } \bmod 2 \Pi)\end{array}$} & 3 & -16 & -70 & -646 & -52 & -46 & -164 & -222 & -672 \\
\hline & 5 & -8 & 52 & 464 & -14 & -42 & -26 & -18 & 138 \\
\hline & 7 & -4 & -32 & -354 & 6 & 36 & 64 & 66 & 22 \\
\hline \multirow{3}{*}{$\begin{array}{l}\text { Real part of the harmonic } \\
\text { (in } \mathrm{dB} \text { ) }\end{array}$} & 3 & 4 & -24 & 8 & -92 & -130 & -240 & -304 & -540 \\
\hline & 5 & -2 & -4 & 12 & 28 & 52 & 150 & 192 & 422 \\
\hline & 7 & 2 & -2 & -40 & -18 & -16 & -68 & -94 & -254 \\
\hline
\end{tabular}


The imaginary parts of the harmonic, which corresponds to the signal phase, are often used to verify the pertinence of the experimental data. Figure 7, which represents the relation between the imaginary parts of the harmonics and the austenitizing time, shows that the values associated to sample $\mathrm{C}$ are not in accordance with the results obtained for the others samples. They will not be considered in the rest of the paper.

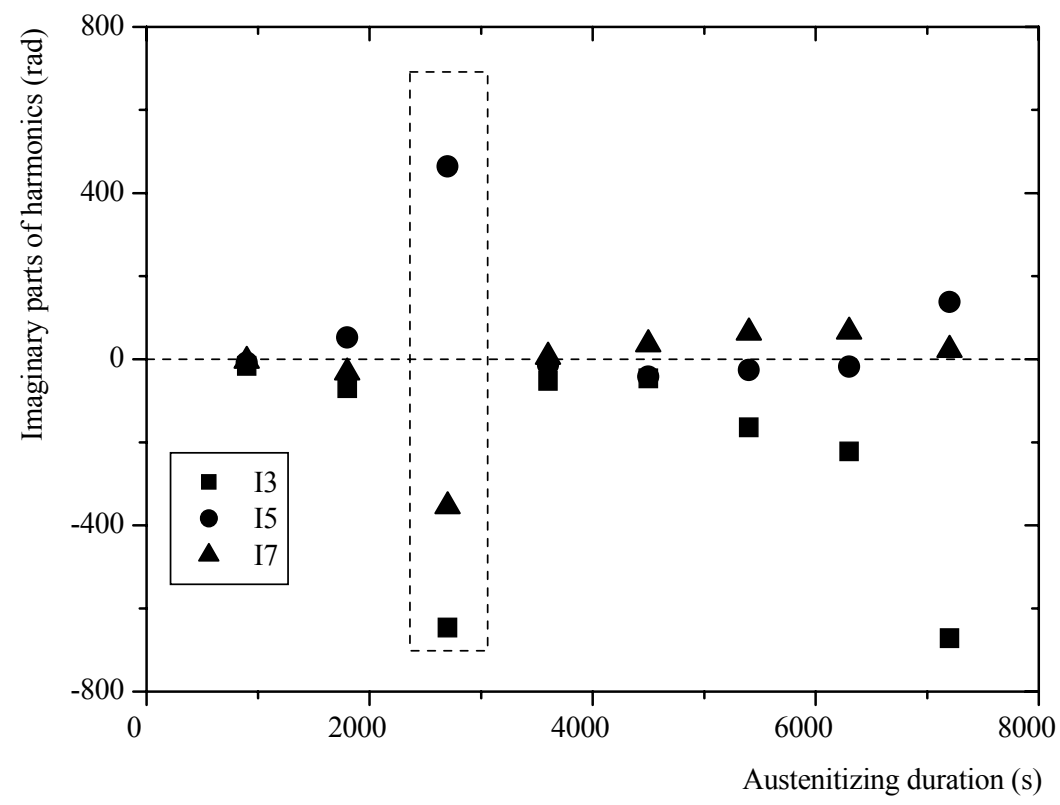

Figure 7: Imaginary parts of the 3, 5 and 7 harmonics as a function of the austenitizing time.

Figure 7 shows the results associated to the real parts of the harmonics as a function of the austenitizing time.

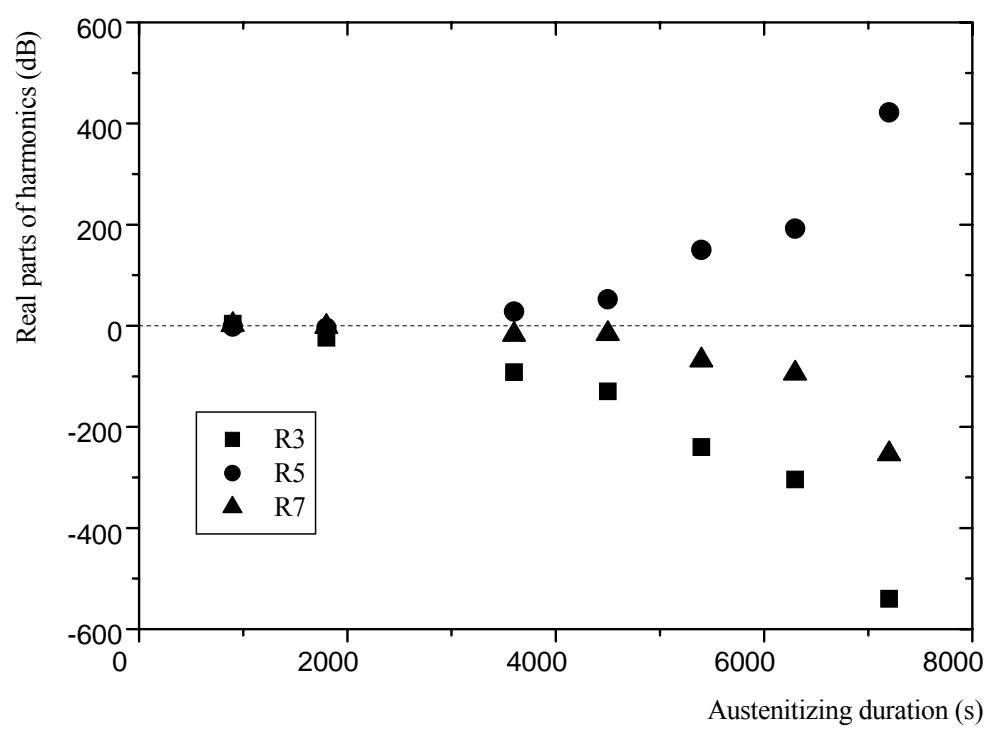

Figure 8: Real parts of the harmonics depending on the austenitizing time.

As it can be noticed on Figure 8, the amplitude of the signal increases with the austenitizing time and consequently with the extent of decarburizing. Replacing the austenitizing time by the corresponding decarburizing depth collected in Table 3, we obtain the Figure 9 presenting this relation between the real parts of the harmonics and the decarburizing depth. 


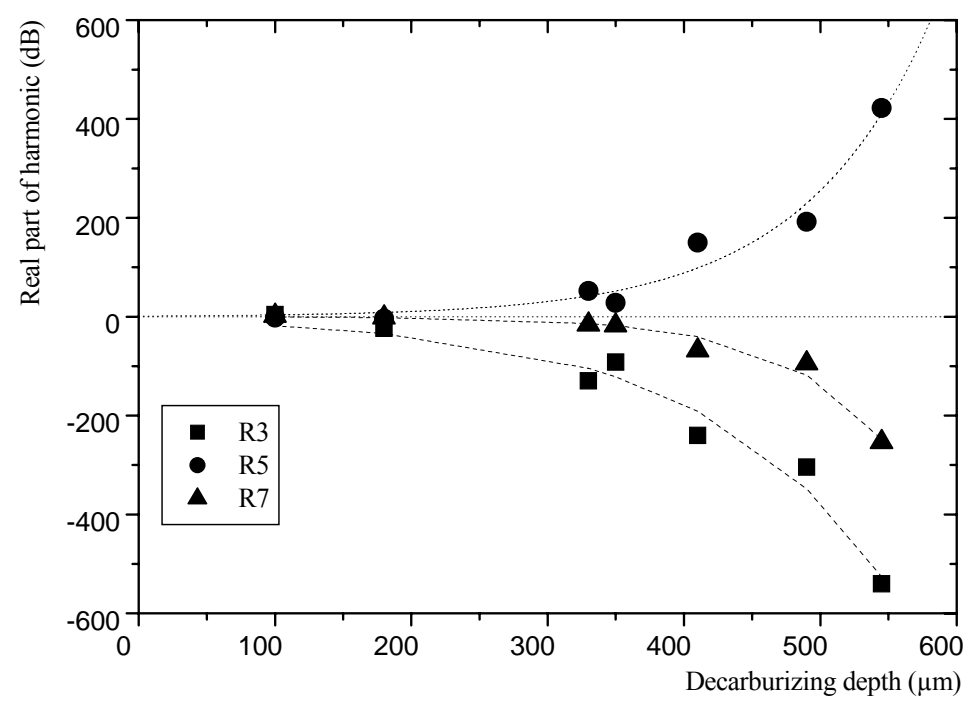

Figure 9: Real parts of the harmonic as a function of decarburizing depth (hardness measurement).

Figure 9 shows that significant variations of the harmonics of the eddy current signal can be related to the extent of the decarburizing. For the present study only one of the harmonics, harmonic 3 for example, could be used to represent the decarburizing. We will show in the following that the three harmonics are well related. A very simple exponential relation can be used to represent their evolution in function of the depth :

$$
\mathrm{R}_{\mathrm{i}}= \pm \exp \left[\mathrm{A}_{\mathrm{i}}+\mathrm{B}_{\mathrm{i}} \cdot \mathrm{x}\right]
$$

where $R_{i}$ is the real part of the harmonic (i) and $x$ the depth of decarburizing. Sign (-) is used for harmonics 3 and 7 and sign $(+)$ for harmonic 5 .

$A_{i}$ and $B_{i}$ are coefficients depending on the harmonic order. As shown Figure 10, they are in accordance together.

Since coefficients $A_{i}$ and $B_{i}$ are determined independently, it confirms that the variation is clearly related to the decarburizing phenomenon, which was determinate by hardness method. But, it is necessary to define precisely the parameters, which characterize the phenomenon in a better way.

Moreover, in order to do more investigations in the future, it is interesting to know the surface properties of the samples. So, we try to correlate the first hardness measured at $20 \mu \mathrm{m}$ near the surface with the real part of the eddy current harmonical response. In Figure 11, we plot in a bi-logarithmic coordinate the surface microhardness and the real part of the harmonics 3,5 and 7 . 


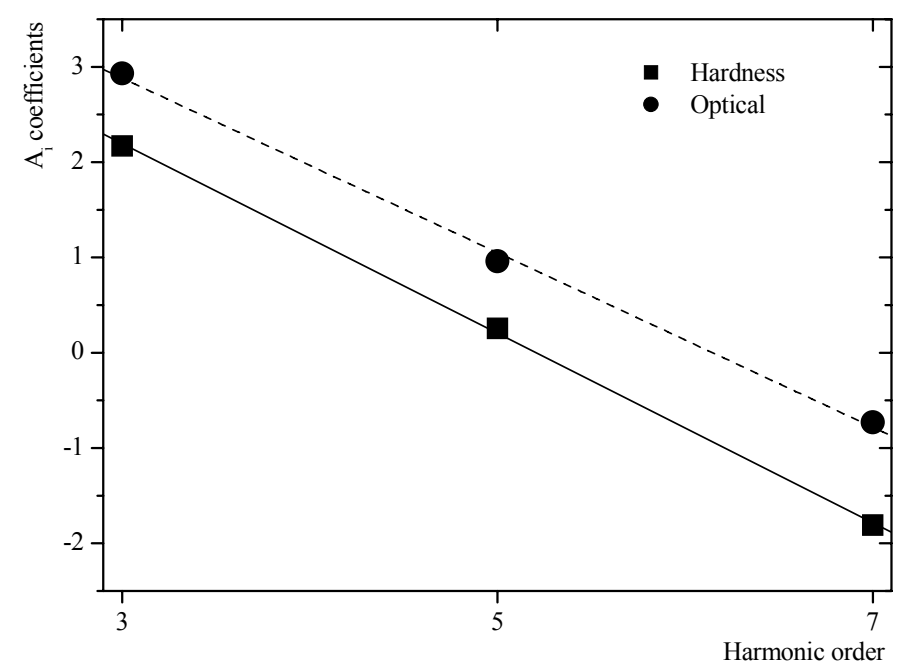

(a)

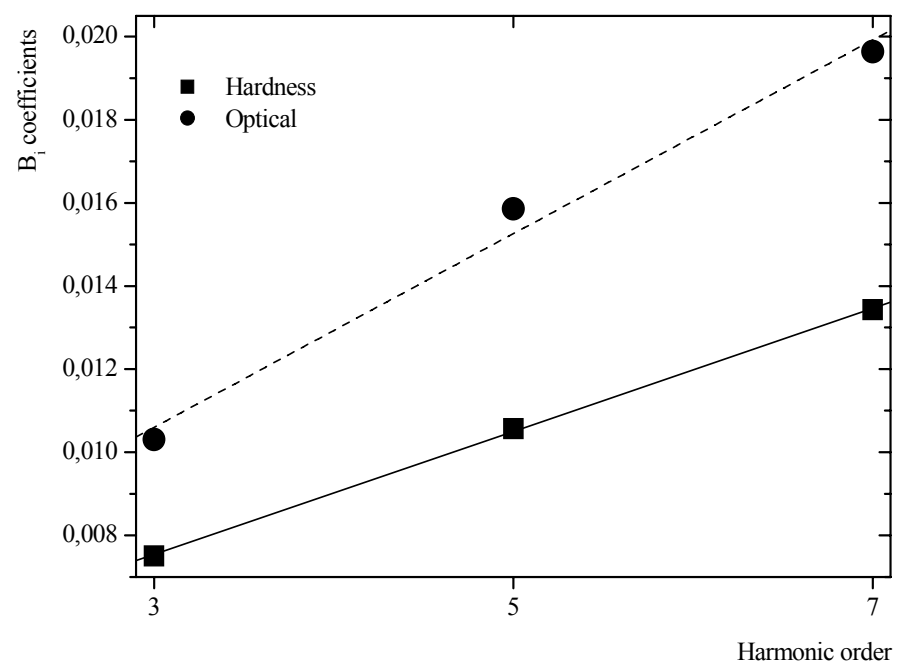

(b)

Figure 10: Coefficients $A_{i}$ and $B_{i}$ relating to the harmonic order.

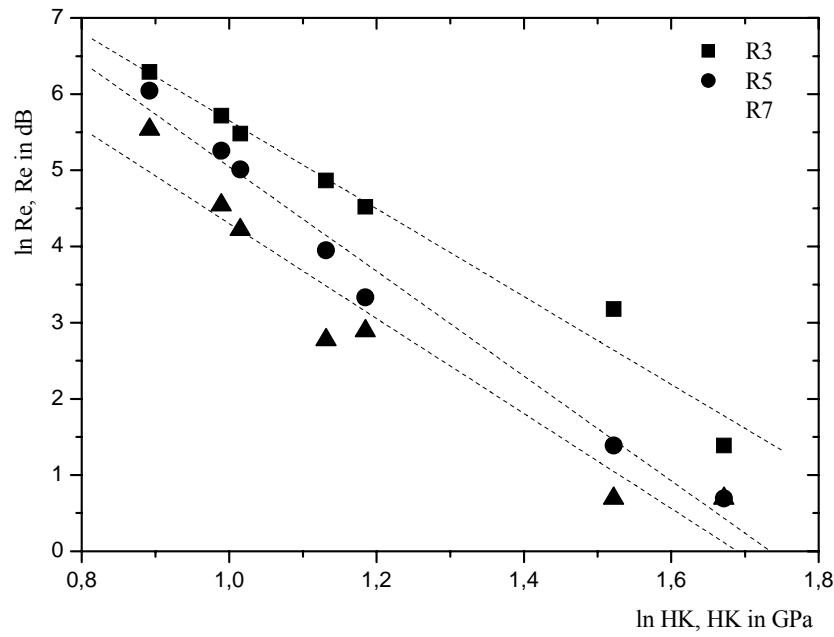

Figure 11: Correlation between surface hardness and the harmonics real parts. 


\section{CONCLUSIONS}

It was shown that the eddy current technique is sensitive to carbon composition, and related to micro-structural state, of the material after heat-treating and quenching. This result is very promising for the future application of the technique for a non-destructive evaluation of the decarburizing phenomenon or carbon surface treatment like carburizing. A first step is to precise how the necessary calibration will be performed between the signal and the decarburizing depth for different conditions of heat treatment and materials. Some work has still to be done, though, to define the methodology to be applied for extensive decarburizing. For low decarburizing, since the carbon content at the material surface can be derived from a simple error function applied to the actual measured depth, only one parameter can be used to describe the decarburization. A second step for the future work will be to define the methodology to consider the change of the relation between the surface carbon content and decarburizing depth and to define the influence of the steel composition, which must be consider in the measurement calibration.

\section{REFERENCES}

[1] PAPAELIAS, M.P., STRANGWOOD, M., PEYTON, A.J., DAVIS, C.L., "Effect of Microstructural Variations on Smart Inductive Sensor Measurements of Phase Transformation in Steel", Scripta Materialia, v. 51, i. 5, pp. 379-383, 2004.

[2] BROWN A.F. HAYES, D.J., "Observations on the Decarburization and Graphitisation of Steels by Sodium", Journal of Nuclear Materials, v. 27, i. 2, pp. 187-193, 1968.

[3] STANDAERT, C., ELOOT, K., DE PAEPE, A., WOKOWSKI, P., "Decarburization of Interlocked and Laser Welded Stator and Rotor Cores", Journal of Magnetism and Magnetic Materials, v. 160, pp. 139-140, 1976.

[4] RADEMAKERS, P.L.F., KOLSTER, B.H., "Corrosion of Various Ferritic Steels in an Isothermal Sodium Loop System", Journal of Nuclear Materials, v. 97, i. 3, pp. 309-318, 1981.

[5] WATERHOUSE, B., TAYLOR, D.E., "The Effect of Heat Treatment and Decarburization on the Fretting Fatigue Behaviour of a 0.7\% Carbon Steel", Proc. Inst. Mech. Engrs. Wear, v. 19, i. 3, pp. 364-365, 1972.

[6] GRANOTTIER, C., "Contribution à l'étude de la tenue en fatigue des ressorts formés à chaud: Influences cumulés des paramètres de surface”, D.Sc. thesis, ECL, France, 1982.

[7] VÖHRINGER, O., MACHERAUD, E., HTM 32 , pp. 153-166, 1977.

[8] KURJUMOV, G.V., "Martensite Crystal Lattice, Mechanism of austenite-martensite Transformation and Behavior of Carbon Atoms in Martensite", Metall. Trans., v. 7A, pp. 999-1011, 1976.

[9] RESTIVO, M.T., “A Case Study of Induced Eddy Currents", Sensors and Actuators A: Physical, v. 51, i. 2-3, pp. 203-210, 1996.

[10] YUSA, N., CHENG, W., UCHIMOTO, T. MIYA, K., "Profile Reconstruction of Simulated Natural Cracks From Eddy Current Signals", NDT \& E International, v. 35, i. ,pp. 9-18, 2002.

[11] ZILBERSTEIN, V., WALRATH, K., GRUNDY, D., GOLDFINE, N., ABRAMOVICI, E., YENTZER, T., "MWM Eddy-Current Arrays for Crack Initiation and Growth Monitoring", International Journal of Fatigue, v. 25, i. 9-11, pp. 1147-1155, 2003.

[12] UCHIMOTO, T., TAKAGI, T., KONOPLYUK, S., ABE, T., HUANG, H., KUROSAWA, M., "Eddy Current Evaluation of Cast Irons for Material Characterization", Journal of Magnetism and Magnetic Materials, v. 258-259, pp. 493-496, 2003. 
[13] STEVENS, K.J., PARBHU, A., SOLTIS, J., "Magnetic Force Microscopy and cross-sectional Transmission Electron Microscopy of Carburised Surfaces", Current Applied Physics, v. 4, i. 2-4, pp. 304-307, 2004.

[14] MOORTHY, V., SHAW, B.A., EVANS, J.T., "Evaluation of Tempering Induced Changes in the Hardness Profile of case-carburised EN36 Steel Using Magnetic Barkhausen Noise Analysis", NDT \& E International, v. 36, i. 1, pp. 43-49, 2003.

[15] ZERGOUG, M., LEBAILI, S., BOUDJELlAL, H., BENCHAALA, A., "Relation Between Mechanical Microhardness and Impedance Variations in Eddy Current Testing”, NDT \& E International, v. 37, pp. 65-72, 2004.

[16] AGREN, J., "A Simplified Treatment of the Transition From Diffusion Controlled to Diffusion-less Growth”, Acta Metall, v. 37, pp 181-189, 1989.

[17] ROY, J., MANNA, I., "Mathematical Modeling of Localized Melting Around Graphite Nodules During Laser Surface Hardening of Austempered Ductile Iron", Optics and Lasers in Engineering, v. 34, pp. 369-383, 2000.

[18] GAMSJAGER, E., ANTRETTER, T., SCHMARANZER, C., PREIS, W., CHIMANi, C.M., SIMHA, N.K., SVOBODA, J., FISHER, F.D., "Diffusional Phase Transformation and Deformation In Steels”, Computational Materials Science, v. 25, pp. 92-99, 2002.

[19] LAN, Y.J., LI, D.Z., Li, Y.Y., "Modelling Austenite Decomposition into Ferrite at Different Cooling Rate in low-carbon Steel With Cellular Automaton Method", Acta Materialia, v. 52, pp.1721-1729, 2004.

[20] KUMAR, M., SASIKUMAR, R., KESAVAN NAIR, P., "Competition Between Nucleation and Early Growth of Ferrite From Austenite - Studies Using Cellular Automaton Simulations", Acta Materialia, v. 46, i. 17, pp. 6291-6303, 1998.

[21] GOLOVIN, I.S., NILSSON, J.O., SERHANTOVA, G.V., GOLOVIN, S.A., “Anelastic Effects Connected With Isothermal Martensitic Transformations in 24Ni4Mo Austenitic and $12 \mathrm{Cr} 9 \mathrm{Ni} 4 \mathrm{Mo}$ Maraging Steels", Journal of alloys and Compounds, v. 310, pp. 411-417, 2000.

[22] ERDOGAN, M., TEKELI, S., "The Effect of Martensite Particle Size on Tensile Fracture of Surface Carburized AISI 8620 Steel with Dual Phase Core Structure", Material and design, v. 23, pp. $597-$ 604, 2002.

[23] MURRY, G., “Transformation Dans les Aciers”, Techniques de l’Ingénieur, article M1-115, ed. $2,1998$.

[24] ROZENDAAL, H.C.F., MITTEMEIJER, E.J., COLJIN, P.G., VAN DER SCHAAF, P.J., Metall. Trans, v. 14 , pp. $395,1983$. 